\title{
Trends of mortality from Alzheimer's disease in the European Union,
}

\section{4-2013}

Hao Niu ${ }^{\mathrm{a}}$ MPH, Ismael Alvarez-Alvarez ${ }^{\mathrm{a}}$ MPH, Francisco Guillen-Grima ${ }^{\mathrm{a}, \mathrm{b}, \mathrm{c}} \mathrm{PhD}$, Moad J Al-Rahamneh ${ }^{\mathrm{a}} \mathrm{MSc}$, Ines Aguinaga-Ontoso ${ }^{\mathrm{a}} \mathrm{PhD}$

\section{Affiliations:}

${ }^{a}$ Department of Health Sciences, Public University of Navarre, Avenida Barañain s/n, 31008, Pamplona, Navarre, Spain.

bNavarre's Institute for Health Research (IDISNA), Irunlarrea 3, 31008, Pamplona, Navarre, Spain.

'Preventive Medicine, University of Navarre Clinic, Pio XII 36, 31008, Pamplona, Navarre, Spain.

\section{Corresponding author:}

Hao Niu

Department of Health Sciences, Public University of Navarre. Avenida Barañain s/n; 31008. Pamplona, Navarre, Spain.

E-mail: niu.74609@e.unavarra.es

This is the peer reviewed version of the following article: Niu H, Alvarez-Alvarez I, Guillen-Grima F, Al-Rahamneh MJ, Aguinaga-Ontoso I. Trends of mortality from Alzheimer's disease in the European Union, 1994-2013. Eur J Neurol 2017; 24(6): 858866, which has been published in final form at https://doi.org/10.1111/ene.13302. This article may be used for non-commercial purposes in accordance with Wiley Terms and Conditions for Use of Self-Archived Versions. 


\begin{abstract}
Background: In many countries, Alzheimer's disease (AD) has gradually become a relevant disease in elderly populations. The aim of this study was to analyse trends of mortality caused by AD in the 28 member countries in the European Union (EU) over the last two decades.
\end{abstract}

Methods: We extracted data for AD deaths for the period 1994-2013 in the EU from the Eurostat and World Health Organization database. Age-standardised mortality rates per 100,000 were computed. Joinpoint regression was used to analyse the trends and compute the annual percent change (APC) in the EU as a whole and by country. Analyses by gender and by European regions were conducted.

Results: Throughout the study period, mortality from AD has risen in the EU. Most of the countries showed upward trends, with the sharpest increases in Slovakia, Lithuania and Romania. In men and women, we recorded a $4.7 \%$ and $6.0 \%$ statistically significant increase in mortality rates in the whole EU, respectively. Several countries showed changing trends during the study period. According to the regional analysis, Northern and Eastern countries showed the steepest increases, while in the latter years in Western countries mortality has declined.

Conclusions: Our findings provide evidence that AD mortality has increased in the EU, especially in Eastern and Northern European countries and in the female population. Our results could be a reference for the development of primary prevention policies.

Keywords: Alzheimer’s disease; Mortality; Trends; European Union; Joinpoint analysis 


\section{Introduction}

Alzheimer's disease (AD) is defined by the World Health Organization (WHO) as a degenerative cerebral disease of unknown etiology, with characteristic neuropathological and neurochemical features [1].

With the progressive increase in life expectancy, $\mathrm{AD}$ has become an increasing public health issue. In 2013, the Global Burden of Disease Study found that AD was one of the top 50 global causes of years of life lost which experienced a more pronounced increase in the past years [2], and it has been estimated the disease will be the seventh cause of death in high income countries in the year 2030 [3].

Previous studies described increasing trends in mortality from AD in the United States, where the mortality rate rose from 45.3 in 1999 to 50.0 per 100,000 in 2008 [4], and in Canada, where the crude mortality rate for men and women increased from 10.1 to 11.5 per 100,000 and 24.4 to 25.4 per 100,000, respectively, between 2004 and 2011 $[5]$.

However, to date, no studies have been conducted at a European level using a consistent methodology, estimating significant changes in trends. Therefore, the aim of this study was to analyse trends of mortality caused by AD in the European Union (EU) in the period 1994-2013.

\section{Methods}

Data from men and women over 50 years of age from the 28 member countries of the EU in the period 1994-2013 were extracted from the statistical office of the EU (Eurostat) (http://ec.europa.eu/eurostat/data/database) [6]. The WHO database was used when data were not available (http://data.euro.who.int/dmdb/) [7], extracting data from Belgium (2000-2002), Denmark (2010), Germany (1998-2008), France (2011), Croatia 
(1995-1998), The Netherlands (1996-2006), Poland (1999-2004), and Slovakia (19941995). Databases were updated in April 2016 and December 2015, respectively. Both databases receive data from each country's statistical authorities, and no further analyses are conducted. Thus we assume data do not differ substantially, and do not have a significant effect on the results.

During the study period, two different revisions of the International Classification of Diseases (ICD) were used (ICD $9^{\text {th }}$ and $10^{\text {th }}$ revisions). AD deaths were recorded according to the ICD-9 code 331.0 and ICD-10 code G30.

Estimates of resident population, based on official censuses, were also extracted from the Eurostat database (updated on April 2016) [6]. Due to the study design, no approval by an institutional review board was needed.

The 28 EU member countries and their available data included: Belgium (19982013), Bulgaria (2005-2013), Czech Republic (1994-2013), Denmark (1994-2013), Germany (1998-2013), Estonia (1997-2013), Ireland (1997-2013), Greece (1994-2013), Spain (1994-2013), France (metropolitan) (1994-2011), Croatia (1995-2013), Italy (2001-2003, 2006-2013), Cyprus (2004-2013), Latvia (1996-2013), Lithuania (19942013), Luxembourg (1998-2013), Hungary (1994-2013), Malta (1995-2011, 2013), the Netherlands (1996-2013), Austria (1994-2013), Poland (1999-2013), Portugal (19942000, 2002-2013), Romania (1999-2013), Slovenia (1995-2013), Slovakia (1994-2013), Finland (1996-2013), Sweden (1994-2013), and the United Kingdom (1994-2013). Unfortunately, data for one or more calendar years were missing from a few countries. No extrapolation was made for missing data. We assume that in those countries with less missing data, trends would not notably vary. Conversely, in those countries with more missing data, results could have been affected to a certain extent, and should be interpreted carefully. 
From the matrices of certified death and resident population, age-standardised mortality rates per 100,000 for each 5-year age group (from 50-54 to 85 and more) and calendar period for men and women were computed, using the direct method and based on the 2013 European Standard Population.

We also conducted an analysis to assess regional mortality trends, distinguishing four European regions: Northern (Denmark, Estonia, Finland, Ireland, Latvia, Lithuania, Sweden, and the United Kingdom), Southern (Croatia, Cyprus, Greece, Italy, Malta, Portugal, Slovenia, and Spain), Eastern (Bulgaria, Czech Republic, Hungary, Poland, Romania, and Slovakia), and Western Europe (Austria, Belgium, France, Germany, Luxembourg, and the Netherlands).

We used the Joinpoint regression software (version 4.2.0.2) provided by the Surveillance Research Program of the USA National Cancer Institute to analyse significant changes in mortality trends. This analysis identifies inflexion points (called “joinpoints") at which there is a significant change in the linear slope of the trend [8]. The number and location of significant joinpoints for each country were determined using a log-linear model. We computed the estimated annual percent change (APC) and corresponding 95\% confidence intervals (95\% CIs), which describes the magnitude of change for each of the identified trends. In this model, age-standardised mortality rates were used as the dependent variable, and the year of death as the independent variable. In all analyses, a p value lower than 0.05 was regarded as statistically significant.

\section{Results}

Between 1994 and 2013, the number of recorded deaths from AD in the EU increased steadily from 41,255 (13,508 men and 27,747 women) to 86,822 (26,974 men and 59,848 women). 
Overall age-standardised mortality rate increased from 28.18 to 45.19 per 100,000. In 1994, the highest rates were found in France (20.58 per 100,000), and the lowest in Lithuania (0.43 per 100,000). In 2013, Finland had the highest mortality rate (278.92 per 100,000), while the lowest were observed in Malta and Latvia (below 5 per 100,000). (Table S1)

According to our findings, during the 2004-2013 period the entire EU showed a 5.6\% statistically significant increase, with no identifiable joinpoints. Mortality rates rose over the last two decades in 26 countries throughout the EU. Slovakia and Romania had the biggest increases (APC $=26.0 \%$ and $\mathrm{APC}=22.7 \%$, respectively), while Luxembourg $(\mathrm{APC}=1.2 \%)$ and Latvia (APC $=2.8 \%)$ showed the slightest increases. Only in Malta $(\mathrm{APC}=-4.1 \%)$ and Germany $(\mathrm{APC}=-0.4 \%)$ were declining trends observed.

Trends of mortality from $A D$ by gender

Age-standardised mortality rates for men are presented in Table S2. In 1994, the highest rates were observed in France, Spain and Czech Republic (over 10 per 100,000), and the lowest in Lithuania, Slovakia, Greece and Hungary (below 2 per 100,000). In 2013, Finland had the highest male rates (270.02 per 100,000), while the lowest were found in Malta, Greece and Bulgaria (below 6 per 100,000).

Throughout the EU, men showed a statistically significant increase in mortality (APC $=4.7 \%$ ), with no joinpoints observed. Mortality rates between 1994 and 2013 rose in 25 countries. Slovakia, Romania and Lithuania had the largest increases, while for Poland, Greece and Belgium we observed less pronounced increases. In contrast, only Germany, Malta and Luxembourg showed an overall downward trend. (Table 1)

For eleven countries which had an overall upward trend (Hungary, Lithuania, Romania, Greece, Italy, Sweden, Croatia, Portugal, the United Kingdom, Spain, and 
Denmark) APCs peaked, increasing at a lower rate or decreasing thereafter. For three countries (Austria, Slovakia and Czech Republic) we observed fluctuating mortality trends, with non-significant decreases, followed by pronounced increases.

For women, the highest rates in 1994 were recorded in France, Spain and Czech Republic (over 14 per 100,000), and the lowest in Slovakia and Lithuania (below 1 per 100,000). In 2013, we observed in Finland the highest female rate (over 280 per 100,000), and the lowest in Malta, Latvia and Bulgaria (below 7 per 100,000). (Table S3)

Among European women, we recorded a 6.0\% steady and statistically significant increase, without identifying any joinpoints. Mortality from AD rose in 26 countries. The most pronounced increases were observed in Slovakia, Romania and Lithuania, while Latvia and Luxembourg showed the smallest increases. In Germany rates levelled off, and only Malta showed a declining trend. (Table 2)

In twelve countries with an overall upward trend (Slovakia, Romania, Hungary, Sweden, Slovenia, Denmark, France, Italy, Poland, Portugal, Spain, and the United Kingdom), APCs peaked and continued increasing at a lower rate. In Latvia and Luxembourg, after the APC peaked we observed a declining trend, and increases thereafter. The Czech Republic, after a decreasing trend, showed the steepest increases in the latter years of the study.

Trends for both men and women are shown graphically in Figure 1. Except for the Czech Republic, Finland, Hungary, Latvia, Lithuania, the Netherlands, and Romania trends were more pronounced in women than in men.

Trends of mortality from $A D$ by region

Results from the regional mortality trends analysis showed the sharpest increase in Northern and Eastern Europe. In Western Europe we observed an overall slight increase, 
and in the period 2009-2013 a statistically significant declining trend, during the same period, in Eastern Europe a pronounced increase was recorded. Since the mid 2000s, in Southern countries rates have levelled off. (Table 3)

\section{Discussion}

The present updated analysis of mortality from AD in the EU showed overall upward trends in both sexes over the past two decades. The largest increases were found in Slovakia, Romania, and Lithuania. In Finland we observed the highest mortality rates, with a steady increase over the study period. Mortality rates levelled off or declined for only two countries, Germany and Malta.

Most of the countries showed increasing mortality trends for both genders. We compared our findings with previous studies. According to the findings of Desesquelles and colleagues [9], in France mortality has been increasing since 1985, which is consistent with our results. An Italian study also showed evidence of an upward trend in the period 1985-2003 in this country, with the steepest increases in the latter years [10]. We only analysed available data in the 2000s, when we also observed a pronounced increase in mortality rates. In England and Wales, mortality rates experienced an 8-fold increase in men and 12-fold increase in women between 1985 and 2004 [11]. According to our findings, the United Kingdom (which also included Scotland and North Ireland) also showed rising trends for both sexes, especially in women.

Economic development and improvement of social conditions over the last decades have led to an increase in life expectancy [12], which might explain the increasing trends in mortality from age-related diseases, especially in Eastern countries (Slovakia, Lithuania, Slovenia, Romania, Hungary), where we observed the lowest mortality rates in the 1990s. 
Several Northern European countries also showed pronounced increasing trends, presumably due not only to the progressive ageing of their population, but also to other factors. Studies have demonstrated evidence that $A P O E \varepsilon 4$ allele frequencies, a wellstudied risk factor for AD [13], are higher in Northern countries [14, 15].

Although it might be thought that increasing mortality rates could be attributed to better diagnostics, Hallberg [16] rejected this idea in Sweden, and remarked on the contribution of environmental factors. However, we cannot discard that better diagnostics and increased awareness of the condition by physicians could explain the increase in mortality rates in other countries.

In many countries, the APC peaked in the early years of the study, when most of the countries implemented ICD-10. Previous studies found a 55\% increase in AD recorded deaths when classified by ICD-10 instead ICD-9 [17], due to the inclusion of pre-senile dementia and a lax criterion of imputation to any mention of $\mathrm{AD}$ [18], which could be the reason why mortality rates rose in this period. Posterior lower increases or declining trends could be attributed to improvements in health services and prevention policies addressing modifiable risk factors. Norton and colleagues [19] showed that in Europe a $10 \%$ reduction per decade of the prevalence of seven modifiable risk factors would result in a $9.1 \%$ reduction of the prevalence of $\mathrm{AD}$ in the future.

In Germany, mortality rates in men declined, while in women they levelled off. Surprisingly, its population is one of the oldest in the entire EU, but this was not reflected in rising mortality trends. Previous studies described decreasing trends in dementia prevalence between 2007 and 2009, suggesting the reason for these trends might be protective factors (better education, economic development) related to the non-war period of the $20^{\text {th }}$ century [20]. We also hypothesised that, due to the characteristics and progress 
of the disease, which might lead to other underlying causes of death, mortality from AD has possibly been underreported [21,22].

Cyprus and Malta were the countries with the smallest populations, and we also observed low mortality figures. It must be taken into account that our results, which showed rising and declining trends, respectively, could be affected by the effect of their small populations.

It is worth noting that, because of the low rate of recording dementia as the cause of death, mortality data were not useful in exploring geographical variation and time trends $[23,24]$. This fact may have contributed to an underestimation of the real AD mortality observed in this study.

Our findings showed pronounced mortality trends for women in most of the countries. Sex differences in AD have been widely studied and attributed to several factors, including genetic, hormonal and social factors, or the longer life expectancy of women $[25,26]$.

When we assessed the regional mortality trends, we observed the biggest increases in Northern and Eastern Europe. In contrast, in the latter study years in Southern Europe mortality rates levelled off, and in Western Europe a declining trend was observed. We hypothesised these differences may be due to lifestyle factors (as well as the social and genetic factors previously stated), such as a higher adherence to the Mediterranean diet, which has been found as a protecting factor for developing $\mathrm{AD}$ [27], and associated with a lower mortality risk [28].

This study has several strengths. To our knowledge, this is the first study analysing AD mortality trends in the whole of the EU. Moreover, mortality data were extracted from official databases. Our study also has limitations. The main limitation is the lack of 
data from some countries. These databases are updated with data from national statistical offices, but in some cases data were not provided for several years. We decided not to extrapolate or impute in order to analyse only official data. Another limitation is the reflection of the condition as an underlying cause of death, but not as a contributing cause of death.

\section{Conclusion}

In conclusion, we confirm mortality from $\mathrm{AD}$ has significantly increased in the $\mathrm{EU}$ in the last two decades, especially in Eastern and Northern Europe and the female population. Consequently, in the upcoming years, the EU will face not only health, but also social and economic challenges. Primary prevention policies addressing to preventable risk factors are recommendable. The effect of diagnostics or medical awareness of the condition deserves further analyses.

Acknowledgments: The authors gratefully acknowledge the English revision made by Kevin P. Dalton, PhD.

Funding: none.

Conflicts of interests: none. 


\section{References}

1. World Health Organization. The ICD-10 classification of mental and behavioural disorders: clinical descriptions and diagnostic guidelines. Geneva: WHO Publication, 1992.

2. GBD Mortality and Causes of Death Collaborators. Global, regional, and national agesex specific all-cause and cause-specific mortality for 240 causes of death, 1990-2013: a systematic analysis for the Global Burden of Disease Study 2013. Lancet 2015; 385: 117-171.

3. Mathers CD, Loncar D. Projections of global mortality and burden of disease from 2002 to 2030. PLoS Med 2006; 3: e442.

4. Moschetti K, Cummings PL, Sorvillo F, Kuo T. Burden of Alzheimer's disease-related mortality in the United States, 1999-2008. J Am Geriatr Soc 2012; 60: 1509-1514.

5. Park J. Mortality from Alzheimer's disease in Canada: a multiple-cause-of-death analysis, 2004 to 2011. Health Rep 2015; 27: 17-21.

6. Eurostat database. http://ec.europa.eu/eurostat/data/database (accessed 23/05/2016).

7. World Health Organization database. http://data.euro.who.int/dmdb/ (accessed 23/05/2016).

8. Kim HJ, Fay Mp, Feuer EJ, Midthune DN. Permutation tests for Joinpoint regression with application to cancer rates. Stat Med 2000; 19: 335-351.

9. Desesquelles A, Demuru E, Salvatore MA, et al. Mortality from Alzheimer's disease, Parkinson's disease and dementias in France and Italy: a comparison using the multiple cause-of-death approach. J Aging Health 2014; 26: 283-315.

10. Frova L, Marchetti S, Pace M, Murianni L, Burgio A. Comparison between hospital discharge and mortality data for Alzheimer's disease in Italy. Ital J Public Health 2011; 8: 186-196. 
11. Griffiths C, Rooney C. Trends in mortality from Alzheimer's disease, Parkinson's disease and dementia, England and Wales, 1979-2004. Health Stat Q 2006; 30: 6-14.

12. Leon DA. Trends in European life expectancy: a salutary view. Int J Epidemiol 2011; 40: $271-277$.

13. Sando SB, Melquist S, Cannon A, et al. APOE $E 4$ lowers age at onset and is a high risk factor for Alzheimer's disease; A case control study from central Norway. BMC Neurol 2008; 8: 9.

14. Corbo RM, Scacchi R. Apolipoprotein E (APOE) allele distribution in the world. Is APOE*4 a “thrifty” allele? Ann Hum Genet 1999; 63: 301-310.

15. Panza F, Solfrizzi V, Torres F, et al. Decreased frequency of apolipoprotein E $E 4$ allele from Northern to Southern Europe in Alzheimer's disease patients and centenarians. Neurosci Lett 1999; 277: 53-56.

16. Hallberg O. Is increased mortality from Alzheimer's disease in Sweden a reflection of better diagnostics? Curr Alzheimer Res 2009; 6: 471-475.

17. Anderson RN, Rosenberg HM. Disease classification: measuring the effect of the Tenth Revision of the International Classification of Diseases on cause-of-death data in the United States. Stat Med 2003; 22: 1551-1570.

18. Cirera Suárez L, Rodríguez Barranco M, Madrigal de Torres E, et al. Correspondencia entre CIE-10 y CIE-9 para las listas de causas de muerte del Instituto Nacional de Estadística y de la Región de Murcia. Rev Esp Salud Pública 2006; 80: 157-175.

19. Norton S, Matthews FE, Barnes DE, Yaffe K, Brayne C. Potential for primary prevention of Alzheimer's disease: an analysis of population-based data. Lancet Neurol 2014; 13: 788-794.

20. Doblhammer G, Fink A, Fritze T. Short-term trends in dementia prevalence in Germany between the years 2007 and 2009. Alzheimers Dement 2015; 11: 291-299. 
21. James BD, Leurgans SE, Hebert LE, Scherr PA, Yaffe K, Bennett DA. Contribution of Alzheimer disease to mortality in the United States. Neurology 2014; 82: 1045-1450. 22. Romero JP, Benito-Leon J, Louis ED, Bermejo-Pareja F. Under reporting of dementia deaths on death certificates: a systematic review of population-based cohort studies. $J$ Alzheimers Dis 2014; 41: 213-221.

23. Martyn CN, Pippard EC. Usefulness of mortality data in determining the geography and time trends of dementia. J Epidemiol Community Health 1988; 42: 134-137.

24. Macera CA, Sun RK, Yeager KK, Brandes DA. Sensitivity and specificity of death certificate diagnoses for dementing illnesses, 1988-1990. J Am Geriatr Socb 1992; 40: 479-481.

25. Mielke MM, Vemuri P, Rocca WA. Clinical epidemiology of Alzheimer's disease: assessing sex and gender differences. Clin Epidemiol 2014; 6: 37-48.

26. Hebert LE, Scherr PA, McCann JJ, Beckett AA, Evans DA. Is the risk of developing Alzheimer's disease greater for women than for men? Am J Epidemiol 2001; 153: 132136.

27. Singh B, Parsaik AK, Mielke MM, et al. Association of Mediterranean diet with mild cognitive impairment and Alzheimer's disease: a systematic review and meta-analysis. $J$ Alzheimers Dis 2014; 39: 271-282.

28. Scarmeas N, Luchsinger JA, Mayeux R, Stern Y. Mediterranean diet and Alzheimer’s disease mortality. Neurology 2007; 69: 1084-1093. 
Table 1. Joinpoint analysis for Alzheimer's disease mortality trends in men in the European Union, 1994-2013.

\begin{tabular}{|c|c|c|c|c|c|c|c|c|}
\hline & \multicolumn{2}{|c|}{ Total study period } & \multicolumn{2}{|c|}{ Period 1} & \multicolumn{2}{|r|}{ Period 2} & \multicolumn{2}{|c|}{ Period 3} \\
\hline & Years & APC $(95 \%$ CI $)$ & Years & APC $(95 \% \mathrm{CI})$ & Years & APC (95\% CI) & Years & APC (95\% CI) \\
\hline European Union & $2004-2013$ & $4.7 *(4.2,5.3)$ & - & - & - & - & - & - \\
\hline Austria & $1994-2013$ & $10.0 *(7.7,12.3)$ & 1994-1999 & $-3.0(-11.8,6.8)$ & $1999-2003$ & $34.3 *(8.5,66.3)$ & $2003-2013$ & $3.5 *(0.1,7.0)$ \\
\hline Belgium & $1998-2013$ & $3.8 *(3.1,4.5)$ & - & - & - & - & - & - \\
\hline Bulgaria & $2005-2013$ & $10.5^{*}(2.7,18.8)$ & 2005-2007 & $48.9(-15.2,161.4)$ & 2007-2013 & $3.3(-6.1,13.6)$ & - & - \\
\hline Croatia & $1995-2013$ & $8.7 *(5.8,11.6)$ & $1995-2000$ & $27.8 *(10.4,47.9)$ & $2000-2013$ & $4.3^{*}(0.8,8.0)$ & - & - \\
\hline Cyprus & 2004-2013 & $4.5(-1.1,10.5)$ & - & - & - & - & - & - \\
\hline Czech Republic & $1994-2013$ & $6.0 *(3.0,9.1)$ & 1994-2006 & $11.2 *(6.9,15.6)$ & 2006-2009 & $-26.2(-62.1,43.7)$ & 2009-2013 & $40.3^{*}(13.6,73.1)$ \\
\hline Denmark & $1994-2013$ & $10.8 *(9.5,12.1)$ & 1994-2006 & $13.9 *(12.2,15.6)$ & 2006-2013 & $4.3 *(0.8,7.9)$ & - & - \\
\hline Estonia & $1997-2013$ & $6.1 *(2.9,9.4)$ & - & - & - & - & - & - \\
\hline Finland & 1996-2013 & $13.7 *(12.7,14.7)$ & 1996-1999 & $6.6(-0.9,14.6)$ & 1999-2007 & $17.3^{*}(15.0,19.6)$ & $2007-2013$ & $9.0 *(6.3,11.7)$ \\
\hline France & $1994-2011$ & $7.4 *(5.8,9.0)$ & $1994-2003$ & $12.8 *(11.4,14.3)$ & 2003-2011 & $1.3(-0.2,2.9)$ & - & - \\
\hline Germany & $1998-2013$ & $-1.8 *(-2.6,-1.0)$ & 1998-2003 & $1.4(-0.8,3.7)$ & 2003-2008 & $-6.0 *(-8.9,-3.0)$ & 2008-2013 & $2.2(-0.0,4.5)$ \\
\hline Greece & $1994-2013$ & $3.7(-0.1,7.7)$ & $1994-2000$ & $35.1 *(24.0,47.1)$ & $2000-2013$ & $-4.9 *(-7.4,-2.4)$ & - & - \\
\hline Hungary & $1994-2013$ & $11.2 *(9.4,13.0)$ & 1994-1996 & $50.9 *(10.3,106.3)$ & 1996-2013 & $9.7 *(8.5,10.9)$ & - & - \\
\hline Ireland & $1997-2013$ & $5.2 *(3.2,7.3)$ & - & - & - & - & - & - \\
\hline Italy & 2001-2013 & $4.7 *(2.1,7.4)$ & 2001-2003 & $33.3^{*}(14.7,55.0)$ & 2003-2013 & $1.7 *(0.0,3.3)$ & - & - \\
\hline Latvia & 1996-2013 & $8.7 *(2.8,15.0)$ & - & - & - & - & - & - \\
\hline Lithuania & $1994-2013$ & $23.2 *(17.6,29.1)$ & 1994-1999 & $81.4^{*}(55.9,111.2)$ & $1999-2013$ & $12.9 *(9.3,16.5)$ & - & - \\
\hline Luxembourg & $1998-2013$ & $-1.5(-5.0,2.1)$ & - & - & - & - & - & - \\
\hline Malta & $1995-2013$ & $-5.8 *(-10.5,-0.9)$ & - & - & - & - & - & - \\
\hline Netherlands & 1996-2013 & $8.7^{*}(7.3,10.0)$ & 1996-2011 & $7.4 *(6.5,8.3)$ & 2011-2013 & $35.8 *(11.7,65.2)$ & - & - \\
\hline Poland & 1999-2013 & $3.4 *(2.5,4.3)$ & - & - & - & - & - & - \\
\hline Portugal & $1994-2013$ & $11.3 *(8.3,14.3)$ & $1994-2003$ & $24.5^{*}(21.4,27.7)$ & 2003-2013 & $0.8(-1.2,2.8)$ & - & - \\
\hline Romania & 1999-2013 & $23.2 *(19.6,26.9)$ & 1999-2004 & $39.6 *(25.7,55.0)$ & 2004-2013 & $16.7^{*}(11.8,21.8)$ & - & - \\
\hline Slovakia & $1994-2013$ & $23.8 *(19.6,28.2)$ & 1994-1996 & $-24.8(-66.0,65.9)$ & $1996-2001$ & $59.8 *(24.4,105.3)$ & 2001-2013 & $15.2 *(9.9,20.7)$ \\
\hline Slovenia & $1995-2013$ & $12.1 *(4.7,20.1)$ & - & - & - & - & - & - \\
\hline Spain & $1994-2013$ & $6.5 *(4.8,8.3)$ & 1994-1997 & $8.2(-1.0,18.2)$ & $1997-2001$ & $21.5^{*}(11.2,32.7)$ & 2001-2013 & $1.6^{*}(0.5,2.6)$ \\
\hline Sweden & $1994-2013$ & $11.6 *(8.9,14.3)$ & 1994-2001 & $27.7 *(21.1,34.6)$ & 2001-2013 & $4.9 *(2.4,7.3)$ & - & - \\
\hline United Kingdom & 1994-2013 & $7.7 *(6.3,9.1)$ & 1994-1999 & $3.2(-2.5,9.2)$ & 1999-2002 & $23.4(-4.2,58.8)$ & 2002-2013 & $4.3 *(2.5,6.0)$ \\
\hline
\end{tabular}

APC: Annual percent change; CI: Confidence intervals

${ }^{*} \mathrm{p}<0.05$ for change in trend. 
Table 2. Joinpoint analysis for Alzheimer's disease mortality trends in women in the European Union, 1994-2013.

\begin{tabular}{|c|c|c|c|c|c|c|c|c|}
\hline & \multicolumn{2}{|c|}{ Total study period } & \multicolumn{2}{|r|}{ Period 1} & \multicolumn{2}{|c|}{ Period 2} & \multicolumn{2}{|c|}{ Period 3} \\
\hline & Years & APC $(95 \%$ CI $)$ & Years & APC $(95 \%$ CI $)$ & Years & APC $(95 \%$ CI $)$ & Years & APC (95\% CI) \\
\hline European Union & $2004-2013$ & $6.0 *(5.3,6.7)$ & - & - & - & - & - & - \\
\hline Austria & 1994-2013 & $11.4 *(9.2,13.7)$ & 1994-1999 & $-4.6(-10.4,1.7)$ & 1999-2003 & $37.6^{*}(19.4,58.6)$ & 2003-2013 & $5.4 *(3.0,7.7)$ \\
\hline Belgium & $1998-2013$ & $4.6^{*}(3.7,5.5)$ & - & - & - & - & - & - \\
\hline Bulgaria & $2005-2013$ & $11.4 *(5.7,17.3)$ & - & - & - & - & - & - \\
\hline Croatia & $1995-2013$ & $10.3 *(7.2,13.4)$ & 1995-1997 & $-10.0(-43.5,43.2)$ & $1997-2001$ & $41.4^{*}(12.1,78.4)$ & 2001-2013 & $3.4 *(0.6,6.3)$ \\
\hline Cyprus & 2004-2013 & $7.7 *(1.1,14.7)$ & - & - & - & - & - & - \\
\hline Czech Republic & $1994-2013$ & $4.0 *(1.1,6.9)$ & 1994-2005 & $10.4 *(6.3,14.5)$ & 2005-2009 & $-21.1(-40.1,3.9)$ & 2009-2013 & $37.3 *(15.4,63.4)$ \\
\hline Denmark & $1994-2013$ & $12.5 *(10.8,14.2)$ & 1994-2004 & $18.2 *(15.7,20.8)$ & 2004-2013 & $6.1 *(3.4,8.8)$ & - & - \\
\hline Estonia & $1997-2013$ & $8.5^{*}(5.5,11.6)$ & - & - & - & - & - & - \\
\hline Finland & $1996-2013$ & $13.0 *(12.3,13.7)$ & $1996-2000$ & $8.2 *(2.8,13.7)$ & $2000-2013$ & $13.9 *(13.0,14.9)$ & - & - \\
\hline France & $1994-2011$ & $8.8 *(7.2,10.5)$ & $1994-2003$ & $14.5 *(13.0,16.0)$ & 2003-2011 & $2.5 *(1.0,4.1)$ & - & - \\
\hline Germany & $1998-2013$ & $0.2(-0.4,0.9)$ & 1998-2002 & $3.6(-0.7,8.2)$ & $2002-2010$ & $-1.6(-3.3,0.2)$ & 2010-2013 & $5.4(-1.5,12.8)$ \\
\hline Greece & $1994-2013$ & $6.1 *(2.6,9.7)$ & $1994-2000$ & $34.0 *(24.4,44.5)$ & $2000-2013$ & $-1.8(-4.0,0.5)$ & - & - \\
\hline Hungary & 1994-2013 & $9.5 *(7.8,11.3)$ & 1994-1996 & $61.0 *(26.2,105.3)$ & 1996-2013 & $7.7 *(6.8,8.6)$ & - & - \\
\hline Ireland & $1997-2013$ & $6.2 *(4.7,7.6)$ & - & - & - & - & - & - \\
\hline Italy & 2001-2013 & $5.6 *(3.0,8.2)$ & 2001-2003 & $32.2 *(10.9,57.5)$ & 2003-2013 & $2.7 *(0.7,4.6)$ & - & - \\
\hline Latvia & $1996-2013$ & $1.6(-1.9,5.2)$ & 1996-2001 & $31.5^{*}(11.5,54.9)$ & 2001-2004 & $-23.4(-63.2,59.8)$ & 2004-2013 & $3.4(-3.3,10.6)$ \\
\hline Lithuania & $1994-2013$ & $20.4 *(16.2,24.8)$ & - & - & - & - & - & - \\
\hline Luxembourg & $1998-2013$ & $2.8 *(1.2,4.4)$ & $1998-2000$ & $32.2 *(4.3,67.5)$ & 2000-2007 & $-1.6(-5.5,2.4)$ & 2007-2013 & $5.6 *(1.4,9.9)$ \\
\hline Malta & $1995-2013$ & $-3.2(-7.7,1.5)$ & - & - & - & - & - & - \\
\hline Netherlands & $1996-2013$ & $7.3 *(5.8,8.9)$ & $1996-2000$ & $-0.2(-7.2,7.3)$ & $2000-2011$ & $7.4 *(5.5,9.3)$ & 2011-2013 & $32.8 *(5.7,66.9)$ \\
\hline Poland & 1999-2013 & $4.4 *(3.6,5.3)$ & 1999-2005 & $7.2 *(5.3,9.1)$ & 2005-2013 & $2.7 *(1.5,3.9)$ & - & - \\
\hline Portugal & $1994-2013$ & $12.1 *(9.1,15.1)$ & $1994-2003$ & $25.3 *(22.8,27.8)$ & 2003-2013 & $1.6 *(0.0,3.2)$ & - & - \\
\hline Romania & 1999-2013 & $22.3 *(19.2,25.5)$ & 1999-2004 & $37.0 *(26.3,48.5)$ & 2004-2013 & $16.4 *(12.7,20.4)$ & - & - \\
\hline Slovakia & $1994-2013$ & $28.6 *(22.6,34.9)$ & 1994-1999 & $87.2 *(49.3,134.8)$ & $1999-2013$ & $18.1^{*}(12.6,23.9)$ & - & - \\
\hline Slovenia & $1995-2013$ & $15.1 *(9.4,21.1)$ & 1995-1999 & $82.3 *(30.4,154.9)$ & 1999-2013 & $6.8^{*}(1.6,12.2)$ & - & - \\
\hline Spain & $1994-2013$ & $8.0 *(5.9,10.0)$ & 1994-2002 & $18.4 *(15.9,21.1)$ & 2002-2013 & $1.8 *(0.4,3.2)$ & - & - \\
\hline Sweden & $1994-2013$ & $13.5 *(9.9,17.3)$ & 1994-1999 & $49.6 *(33.7,67.4)$ & 1999-2013 & $6.7 *(4.2,9.2)$ & - & - \\
\hline United Kingdom & 1994-2013 & $8.6 *(7.2,10.0)$ & 1994-1999 & $6.0 *(0.7,11.6)$ & 1999-2002 & $22.5(-2.7,54.2)$ & 2002-2013 & $5.1 *(3.5,6.7)$ \\
\hline
\end{tabular}

APC: Annual percent change; CI: Confidence intervals

${ }^{*} \mathrm{p}<0.05$ for change in trend 
Table 3. Joinpoint analysis for Alzheimer’s disease mortality trends by European regions.

\begin{tabular}{|c|c|c|c|c|c|c|c|c|}
\hline & \multicolumn{2}{|c|}{ Total study period } & \multicolumn{2}{|c|}{ Period 1} & \multicolumn{2}{|r|}{ Period 2} & \multicolumn{2}{|c|}{ Period 3} \\
\hline & Years & APC (95\% CI) & Years & APC (95\% CI) & Years & APC (95\% CI) & Years & APC (95\% CI) \\
\hline Northern Europe & 1994-2013 & $10.2 *(9.0,11.3)$ & 1994-2002 & $15.0 *(12.1,18.0)$ & $2002-2013$ & $7.2 *(5.5,8.9)$ & - & - \\
\hline Eastern Europe & 1994-2013 & $7.4 *(6.4,8.4)$ & 1994-2005 & $9.5 *(7.5,11.5)$ & 2005-2009 & $-0.8(-13.2,13.4)$ & 2009-2013 & $15.0 *(5.7,25.2)$ \\
\hline Southern Europe & 1994-2013 & $7.0 *(5.2,8.9)$ & 1994-2004 & $13.5^{*}(10.8,16.3)$ & 2004-2013 & $0.0(-2.9,2.9)$ & - & - \\
\hline Western Europe & $1994-2013$ & $3.4^{*}(1.9,5.0)$ & 1994-2009 & $5.8 *(4.7,7.0)$ & $2009-2013$ & $-11.6 *(-18.4,-4.2)$ & - & - \\
\hline
\end{tabular}

APC: Annual percent change; CI: Confidence intervals

${ }^{*} \mathrm{p}<0.05$ for change in trend 
Figure 1. Trends in mortality from Alzheimer's disease in the European Union, 1994-2013
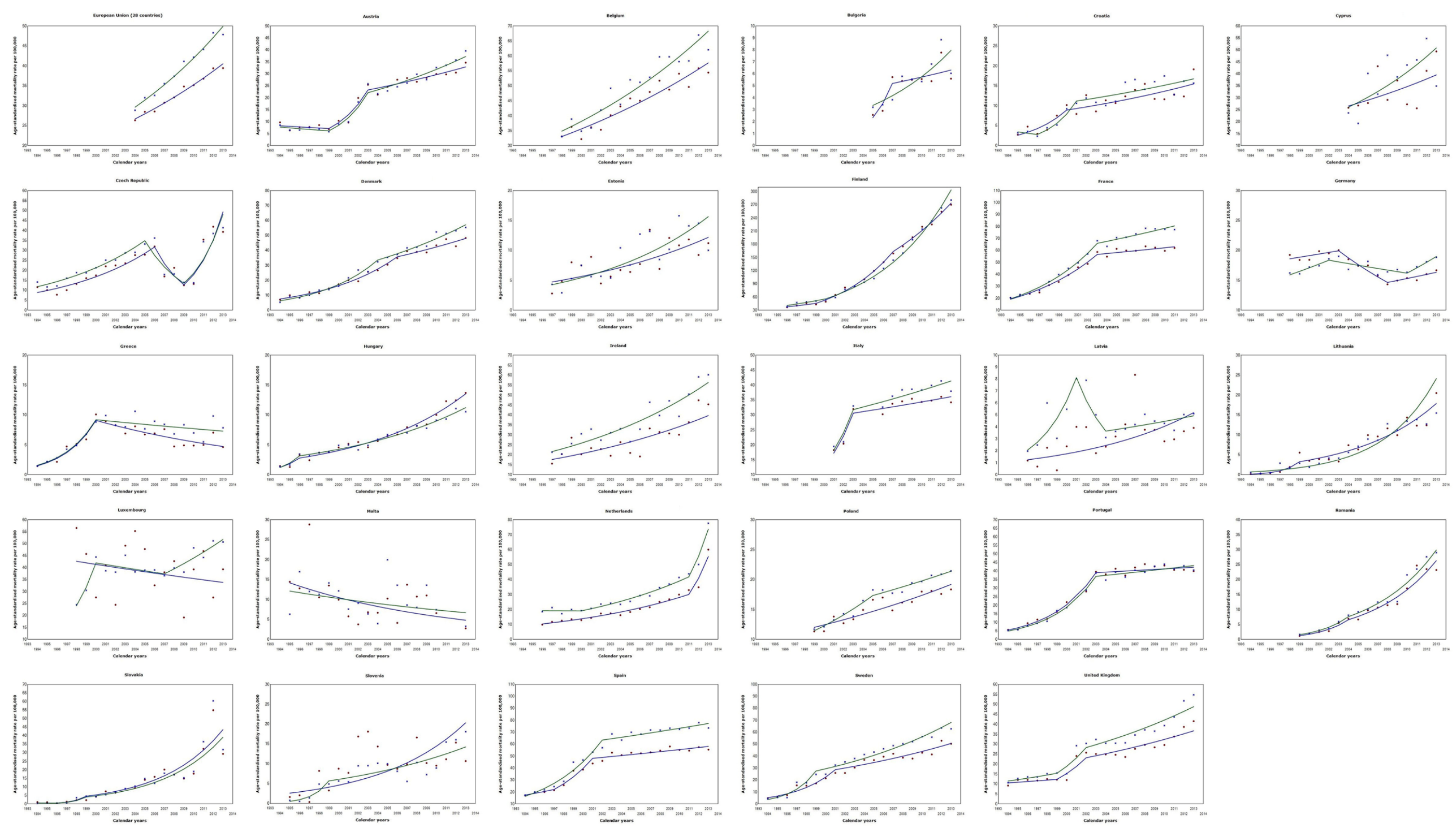


\section{Figure 1 legend}

Blue line: men

Green line: women

Red circle: men (age-standardised mortality rates)

Blue cross: women (age-standardised mortality rates) 
Supplemental table 1. Overall age-standardised mortality rates in the European Union, 1994-2013.

\begin{tabular}{|c|c|c|c|c|c|c|c|c|c|c|c|c|c|c|c|c|c|c|c|c|}
\hline Countries & 1994 & 1995 & 1996 & 1997 & 1998 & 1999 & 2000 & 2001 & 2002 & 2003 & 2004 & 2005 & 2006 & 2007 & 2008 & 2009 & 2010 & 2011 & 2012 & 2013 \\
\hline European Union & & & & & & & & & & & 28.18 & 31.01 & 31.41 & 34.10 & 35.78 & 39.20 & 40.03 & 41.86 & 45.45 & 45.19 \\
\hline Austria & 8.91 & 6.47 & 6.91 & 7.53 & 7.46 & 6.12 & 9.57 & 9.74 & 18.67 & 25.88 & 21.66 & 23.52 & 25.60 & 26.85 & 28.59 & 28.36 & 31.78 & 32.73 & 34.22 & 37.95 \\
\hline Belgium & - & - & - & - & 33.18 & 38.14 & 34.13 & 36.02 & 39.90 & 46.74 & 44.09 & 50.54 & 49.25 & 51.23 & 57.22 & 56.15 & 57.15 & 55.55 & 63.38 & 59.42 \\
\hline Bulgaria & - & 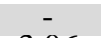 & 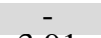 & 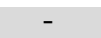 & - & - & - & - & - & - & - & 2.93 & 3.23 & 4.56 & 5.67 & 5.52 & 5.38 & 6.30 & 8.42 & 5.86 \\
\hline Croatia & - & 3.06 & 3.91 & 2.55 & 4.25 & 5.89 & 9.47 & 9.86 & 12.13 & 10.01 & 10.26 & 11.10 & 14.77 & 16.13 & 14.48 & 14.65 & 15.69 & 12.79 & 15.06 & 16.65 \\
\hline Cyprus & -7 & - & - & - & - & - & - & - & - & - & 24.99 & 22.55 & 34.72 & 36.62 & 40.07 & 38.19 & 36.77 & 37.35 & 49.27 & 41.27 \\
\hline Czech Republic & 13.30 & 11.14 & 10.82 & 14.16 & 17.23 & 18.02 & 20.05 & 23.98 & 24.21 & 27.23 & 28.61 & 31.59 & 34.86 & 17.72 & 19.20 & 13.53 & 13.53 & 34.75 & 39.64 & 40.63 \\
\hline Denmark & 5.98 & 9.33 & 8.19 & 10.63 & 12.79 & 14.25 & 16.38 & 21.09 & 24.16 & 25.69 & 30.52 & 33.72 & 36.37 & 40.93 & 40.93 & 41.36 & 49.17 & 50.05 & 49.40 & 53.35 \\
\hline Estonia & - & - & . & 3.72 & 3.16 & 6.49 & 6.79 & 6.37 & 5.24 & 5.64 & 9.33 & 7.28 & 11.68 & 12.79 & 7.98 & 10.47 & 13.97 & 12.90 & 13.22 & 10.02 \\
\hline Finland & & - & 37.75 & 45.42 & 48.31 & 48.53 & 52.26 & 60.51 & 78.25 & 84.37 & 96.43 & 108.23 & 129.76 & 149.05 & 165.35 & 192.87 & 218.10 & 233.03 & 260.96 & 278.92 \\
\hline France & 20.58 & 23.06 & 24.17 & 26.12 & 33.09 & 37.96 & 43.40 & 48.71 & 54.53 & 65.41 & 61.03 & 68.18 & 67.77 & 69.54 & 73.81 & 73.26 & 72.06 & 72.73 & 200.00 & 2.7.0 \\
\hline Germany & 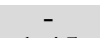 & 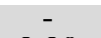 & & - & 17.15 & 16.85 & 17.69 & 18.27 & 18.97 & 19.43 & 17.53 & 17.68 & 18.16 & 16.11 & 15.88 & 16.37 & 16.20 & 16.75 & 17.56 & 18.32 \\
\hline Greece & 1.45 & 2.20 & 2.55 & 4.45 & 4.98 & 6.40 & 9.39 & 9.59 & 8.29 & 7.57 & 9.57 & 7.30 & 8.13 & 8.11 & 5.99 & 6.97 & 6.17 & 5.30 & 8.65 & 6.54 \\
\hline Hungary & 1.36 & 1.46 & 3.37 & 2.91 & 3.69 & 3.84 & 4.76 & 5.11 & 4.61 & 4.80 & 5.82 & 6.65 & 6.93 & 7.21 & 8.16 & 7.96 & 9.44 & 10.15 & 11.51 & 11.46 \\
\hline Ireland & - & - & 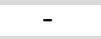 & 19.60 & 20.50 & 27.34 & 27.27 & 29.68 & 25.57 & 27.21 & 30.81 & 24.70 & 28.40 & 42.00 & 37.34 & 41.41 & 36.51 & 45.34 & 55.01 & 54.63 \\
\hline Italy & - & - & 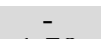 & - & 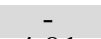 & 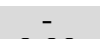 & 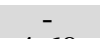 & 19.07 & 20.83 & 32.74 & - & - & 31.97 & 35.46 & 37.21 & 37.71 & 37.18 & 38.25 & 39.77 & 36.90 \\
\hline Latvia & - & - & 1.78 & 1.93 & 4.91 & 2.22 & 4.69 & 7.12 & 6.87 & 4.05 & 2.87 & 3.63 & 3.85 & 4.96 & 4.85 & 4.17 & 3.93 & 3.61 & 4.57 & 4.72 \\
\hline Lithuania & 0.43 & 0.35 & 0.50 & 2.13 & 1.80 & 3.68 & 2.45 & 3.17 & 4.07 & 3.91 & 5.94 & 6.97 & 9. & 8.96 & 12.32 & 10.92 & 13.85 & 13.32 & 12.50 & 16.90 \\
\hline Luxem & - & 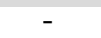 & & & 35.39 & 35.93 & 39.94 & 39.48 & 34.79 & 46.15 & 42.51 & 42.03 & 36.50 & 37.15 & 40.95 & & 45.96 & 46.26 & 44.88 & 47.37 \\
\hline Malta & - & 9.12 & 15.52 & 17.68 & 10.44 & 14.33 & 11.66 & 7.19 & 7.06 & 6.86 & 4.90 & 16.20 & 10.25 & 10.56 & 9.20 & 12.59 & 7.31 & 7.85 & - & 2.85 \\
\hline Netherlands & - & - & 15.94 & 18.50 & 15.96 & 18.16 & 17.47 & 18.74 & 21.74 & 22.17 & 21.40 & 23.35 & 26 & 26.84 & 31.68 & 33.88 & 37.84 & 40.42 & 45.24 & 72.06 \\
\hline Pola & & - & 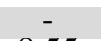 & - & - & 11.61 & 11.88 & 13.46 & 13.76 & 13.75 & & 17.76 & & 16.81 & & & 19.08 & & 19.81 & 20.41 \\
\hline Slov & 0.58 & 0.62 & 0.42 & 0.84 & 3.00 & 3.75 & 4.32 & 6.04 & 7.09 & 8.71 & 10.29 & 14.63 & 13.31 & 18.67 & 17.29 & 15.16 & 18.49 & 35.15 & 58.80 & 31.13 \\
\hline Slovenia & & 1.10 & 1.01 & 1.11 & 5.93 & 4.33 & 6.48 & 6.28 & 11.77 & 11.79 & 11.43 & 10.17 & 8.73 & 6.67 & & & & 14 & 16.02 & 16.24 \\
\hline & 17.35 & 19.94 & 21.19 & 23.48 & 27.85 & 42.57 & 44.10 & 50.16 & 53.22 & 63.42 & 59.26 & 64.35 & 63.06 & 65.66 & 66.07 & 68.30 & 66.58 & 67.08 & 70.96 & 67.47 \\
\hline Sweden & 4.47 & 5.64 & 6.17 & 17.11 & 16.66 & 21.90 & 23.45 & 30.21 & 31.76 & 35.12 & 39.77 & 40.95 & 43.79 & 46.50 & 46.19 & 46.78 & 51.46 & 50.56 & 59.47 & 58.17 \\
\hline ited Kingdom & 10.20 & 12.56 & 13.09 & 12.97 & 14.42 & 14.49 & 14.11 & 27.52 & 29.00 & 29.95 & 28.63 & 28.52 & 28.33 & 32.21 & 34.61 & 33.62 & 35.94 & 40.15 & 46.99 & 49.84 \\
\hline
\end{tabular}


Supplemental table 2. Age-standardised mortality rates in men in the European Union, 1994-2013.

\begin{tabular}{|c|c|c|c|c|c|c|c|c|c|c|c|c|c|c|c|c|c|c|c|c|}
\hline Countries & 1994 & 1995 & 1996 & 1997 & 1998 & 1999 & 2000 & 2001 & 2002 & 2003 & 2004 & 2005 & 2006 & 2007 & 2008 & 2009 & 2010 & 2011 & 2012 & 2013 \\
\hline European Union & - & 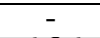 & - & - & - & - & - & 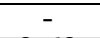 & - & - & 26.36 & 28.48 & 28.57 & 30.77 & 32.10 & 34.84 & 35.18 & 36.80 & 39.40 & 39.45 \\
\hline Austria & 9.74 & 6.36 & 7.70 & 7.80 & 8.61 & 6.89 & 10.41 & 9.69 & 19.95 & 25.47 & 21.33 & 24.60 & 27.56 & 28.25 & 26.71 & 28.35 & 29.95 & 29.79 & 30.53 & 34.69 \\
\hline Belgium & - & - & . & - & 33.09 & 36.30 & 32.18 & 36.16 & 35.31 & 40.19 & 43.13 & 45.79 & 45.03 & 47.96 & 51.73 & 48.74 & 54.07 & 49.63 & 55.87 & 54.43 \\
\hline Bulgaria & - & - & - & - & - & - & - & 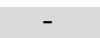 & - & - & 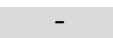 & 2.57 & 2.91 & 5.73 & 5.41 & 5.50 & 5.57 & 5.39 & 7.78 & 5.60 \\
\hline Croatia & - & 2.73 & 4.78 & 2.98 & 3.97 & 7.52 & 10.18 & 7.95 & 12.67 & 8.59 & 11.37 & 10.69 & 12.37 & 13.98 & 15.49 & 11.72 & 11.64 & 12.76 & 12.35 & 19.15 \\
\hline Cyprus & 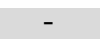 & - & - & - & - & - & - & - & - & - & 25.86 & 26.78 & 27.82 & 43.21 & 29.13 & 37.24 & 27.28 & 25.61 & 41.27 & 49.40 \\
\hline Czech Republic & 11.61 & 10.09 & 7.79 & 10.07 & 13.17 & 16.08 & 17.46 & 22.04 & 22.47 & 23.57 & 27.65 & 27.85 & 31.97 & 16.95 & 21.28 & 12.51 & 13.18 & 35.39 & 41.89 & 39.31 \\
\hline Denmark & 7.09 & 10.03 & 8.41 & 12.09 & 11.35 & 14.55 & 17.34 & 20.08 & 19.35 & 25.67 & 26.67 & 30.47 & 34.81 & 39.44 & 39.05 & 38.65 & 43.40 & 47.56 & 42.79 & 48.29 \\
\hline Estonia & - & 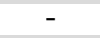 & 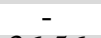 & 2.80 & 4.87 & 8.02 & 7.48 & 8.92 & 4.48 & 5.63 & 6.72 & 6.40 & 7.72 & 13.47 & 6.91 & 12.09 & 10.85 & 11.83 & 9.24 & 11.22 \\
\hline Finland & 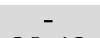 & 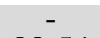 & 36.56 & 40.57 & 45.93 & 43.20 & 49.42 & 64.82 & 81.65 & 84.24 & 100.46 & 119.54 & 139.32 & 159.14 & 175.22 & 196.00 & 219.90 & 225.24 & 254.24 & 270.02 \\
\hline Germany & 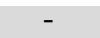 & 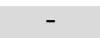 & 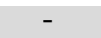 & - & 19.25 & 18.41 & 18.43 & 19.87 & 19.51 & 20.04 & 18.52 & 17.42 & 17.50 & 15.77 & 14.33 & 14.96 & 15.38 & 15.01 & 16.04 & 16.68 \\
\hline Gr & 1.46 & 2.19 & 2.17 & 4.73 & 5.17 & 5.93 & 10.10 & 8.96 & 8.29 & 6.91 & 8.10 & 6.75 & 6.93 & 7.64 & 4.74 & 4.92 & 4.89 & 5.00 & 7.05 & 4.64 \\
\hline Hungary & 1.47 & 1.30 & 3.31 & 2.44 & 3.71 & 3.77 & 4.58 & 5.18 & 5.48 & 4.61 & 5.64 & 6.48 & 6.75 & 7.96 & 8.17 & 8.44 & 10.02 & 12.31 & 12.47 & 13.70 \\
\hline Ireland & - & 年 & 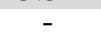 & 15.61 & 20.38 & 28.61 & 20.30 & 23.38 & 22.91 & 19.55 & 26.38 & 20.99 & 19.20 & 33.26 & 31.46 & 30.75 & 30.11 & 36.38 & 47.41 & 45.36 \\
\hline Italy & - & - & - & - & 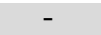 & - & - & 18.27 & 20.40 & 31.99 & 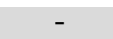 & 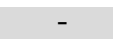 & 30.26 & 33.75 & 34.57 & 35.44 & 34.36 & 34.82 & 36.10 & 34.23 \\
\hline Latvia & 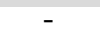 & 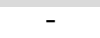 & 1.19 & 0.69 & 2.26 & 0.38 & 2.38 & 4.01 & 3.99 & 1.81 & 2.35 & 3.20 & 4.22 & 8.36 & 3.77 & 3.76 & 2.80 & 2.97 & 3.64 & 3.92 \\
\hline Lithuania & 0.19 & 0.38 & 0.40 & 0.71 & 1.96 & 5.56 & 3.50 & 3.93 & 3.82 & 3.34 & 7.42 & 6.35 & 9.96 & 9.62 & 11.64 & 9.94 & 14.37 & 12.34 & 12.42 & 20.51 \\
\hline Luxembourg & - & - & 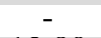 & - & 56.59 & 45.73 & 27.55 & 40.96 & 24.45 & 49.18 & 55.29 & 47.76 & 32.61 & 38.06 & 42.70 & 19.16 & 39.27 & 46.92 & 27.50 & 39.30 \\
\hline Malta & - & 14.45 & 12.80 & 8.82 & 10.55 & 13.51 & 9.96 & 5.77 & 3.77 & 6.80 & 6.68 & 10.24 & 4.14 & 13 & 73 & 11.02 & 6.59 & 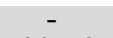 & & 2.77 \\
\hline Nethel & - & 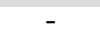 & 9.88 & 11.75 & 12.51 & 13.47 & 12.87 & 14.33 & 17.30 & 17.41 & 16.19 & 18.30 & 20.27 & 21.52 & 10 & 26.81 & 29.96 & 32.98 & 34.86 & 60.04 \\
\hline Pol & 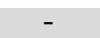 & & & & & 11.34 & 11.36 & 13.81 & 12.71 & 13.37 & 14.93 & 16.63 & 16.99 & 14.85 & & & 17.99 & 18.11 & 17.60 & 18.36 \\
\hline Slov & 1.08 & 1.01 & 0.45 & 1.33 & 2.27 & 2.27 & 4.26 & 7.37 & 6.62 & 8.80 & 9.37 & 14.11 & 15.89 & & 17.14 & & 17.74 & 32.25 & & 29.32 \\
\hline Slovenia & 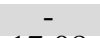 & 1.62 & 2.05 & 0.35 & 8.20 & 3.25 & 8.75 & 7.70 & 16.86 & 18.09 & 14.34 & 9.72 & 8.70 & 9.89 & 16.60 & 10.17 & 9.50 & 11.13 & 15.32 & 10.68 \\
\hline Spain & 17.08 & 19.72 & 19.97 & 21.38 & 25.69 & 37.81 & 38.76 & 43.85 & 46.03 & 52.87 & 50.85 & 52.82 & 52.34 & 53.18 & 54.62 & 58.07 & 55.17 & 54.58 & 57.49 & 55.45 \\
\hline Sweden & 4.87 & 5.96 & 7.41 & 15.58 & 15.31 & 17.19 & 21.43 & 25.93 & 25.89 & 30.39 & 36.87 & 36.67 & 39.54 & 42.00 & 38.73 & 37.97 & 42.85 & 41.41 & 52.89 & 50.35 \\
\hline United Kingdom & 9.23 & 12.04 & 12.06 & 11.73 & 12.50 & 12.20 & 12.01 & 24.07 & 25.73 & 25.06 & 24.85 & 24.67 & 23.58 & 27.65 & 29.67 & 28.41 & 29.60 & 33.84 & 38.65 & 41.52 \\
\hline
\end{tabular}


Supplemental table 3. Age-standardised mortality rates in women in the European Union, 1994-2013.

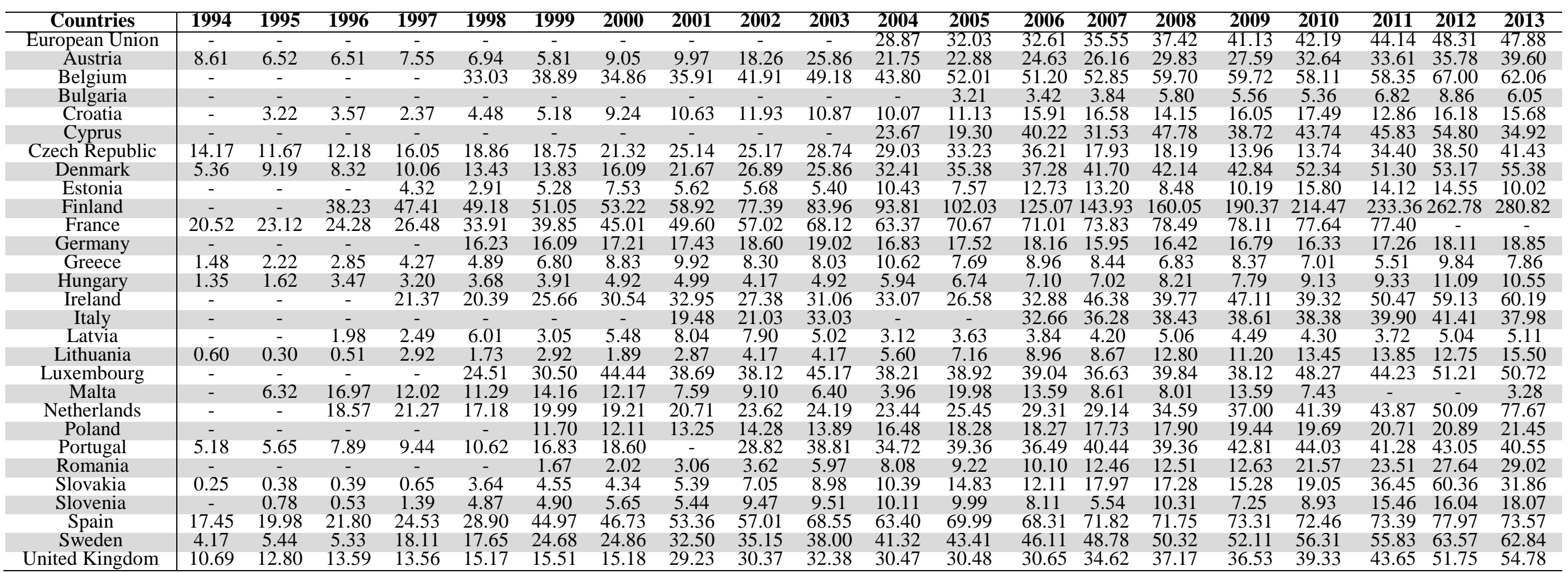

